\title{
Modulation of Fibrosis in Systemic Sclerosis by Nitric Oxide and Antioxidants
}

\author{
Audrey Dooley, ${ }^{1}$ K. Richard Bruckdorfer, ${ }^{2}$ and David J. Abraham ${ }^{1}$ \\ ${ }^{1}$ Centre for Rheumatology and Connective Tissue Disease, University College London Medical School, Royal Free Campus, \\ London NW3 2PF, UK \\ ${ }^{2}$ Institute of Structural and Molecular Biology, University College London Medical School, Gower Street, London WC1E 6BT, UK \\ Correspondence should be addressed to Audrey Dooley, a.dooley@ucl.ac.uk
}

Received 29 July 2011; Accepted 11 September 2011

Academic Editor: Janice Tsui

Copyright (๑) 2012 Audrey Dooley et al. This is an open access article distributed under the Creative Commons Attribution License, which permits unrestricted use, distribution, and reproduction in any medium, provided the original work is properly cited.

Systemic sclerosis (scleroderma: SSc) is a multisystem, connective tissue disease of unknown aetiology characterized by vascular dysfunction, autoimmunity, and enhanced fibroblast activity resulting in fibrosis of the skin, heart, and lungs, and ultimately internal organ failure, and death. One of the most important and early modulators of disease activity is thought to be oxidative stress. Evidence suggests that the free radical nitric oxide (NO), a key mediator of oxidative stress, can profoundly influence the early microvasculopathy, and possibly the ensuing fibrogenic response. Animal models and human studies have also identified dietary antioxidants, such as epigallocatechin-3-gallate (EGCG), to function as a protective system against oxidative stress and fibrosis. Hence, targeting EGCG may prove a possible candidate for therapeutic treatment aimed at reducing both oxidant stress and the fibrotic effects associated with SSc.

\section{Introduction: Nitric Oxide and Systemic Sclerosis}

The free radical nitric oxide (NO) is an important physiological signalling molecule, potent vasodilator, and mediator of oxidative stress. Nitric oxide is synthesised from L-arginine by NO synthase (NOS), and three main isoforms of NOS have been identified with a constitutive expression in neuronal (nNOS or NOS 1), endothelial (eNOS or NOS 3), and several other cell types including fibroblasts. Furthermore, an inducible expression (iNOS or NOS 2) in response to a variety of inflammatory stimuli is possible [1]. Although NO is a gas, it is a highly reactive, short-lived, molecule able to rapidly diffuse across cell membranes. Nitric oxide exerts its biological effects by the reaction of $\mathrm{NO}$ with a diverse range of targets such as haem groups, iron and zinc clusters, and cysteine residues. Since the discovery of $\mathrm{NO}$ as a key endothelial-derived vasodilator molecule in cardiovascular physiology and the award of the Nobel Prize in 1998 to Robert F. Furchgott, Ferid Murad, and Louis J. Ignarro, the field of NO research has rapidly expanded to encompass many biomedical areas. Subsequently, NO has been demonstrated to act as a signalling molecule in many other tissues and regulates physiological and cellular processes in a variety of pathologies such as hypertension, cancer, diabetes, and male impotence [1].

In the disease scleroderma (SSc: systemic sclerosis), the metabolism of $\mathrm{NO}$ appears to be profoundly disturbed. There is considerable evidence implicating overproduction of $\mathrm{NO}$ [2-5] and reactive oxygen species (ROS) such as superoxide anions $\left(\mathrm{O}_{2}{ }^{-}\right)$and peroxynitrite $\left(\mathrm{ONOO}^{-}\right)$ $[3,4,6-8]$ in the pathogenesis of SSc, an often fatal rheumatic disease of unknown aetiology. Regulation of NO by endogenous levels of the NOS inhibitor asymmetric dimethylarginine (ADMA) has also recently been proposed [9]. Major features of SSc are enhanced fibroblast activity, collagen overproduction, autoimmunity, and vascular dysfunction [10-12]. There are several classified clinical subgroups, including limited (ISSc) and diffuse (dSSc) cutaneous SSc, which reflect the nature of the disease in their degree of skin sclerosis, immunological profile, and microvascular dysfunction [13, 14]. Endothelial activation and damage are also an early part of this process [14-17]. The nature of the factors that induce endothelial dysfunction is 
still unclear; however, there are several serological biomarkers that reflect the vasculopathy of the disease. These include the vasoconstrictor endothelin [18], cell adhesion molecules such as selectin [19], anti-endothelial antibodies [20], and the vasodilator nitric oxide $[2,3,5]$. While indeed an early modulator of disease activity is thought to be oxidative stress, the etiology of events and role of NO remain unknown. Recent reports suggest that the abnormal production of ROS is linked to fibroblast activation by the increased expression of stimulatory serum autoantibodies to the platelet-derived growth factor receptor in SSc [21].

\section{Fibrosis and Oxidative Stress in Systemic Sclerosis}

In SSc the excessive connective tissue fibrosis is the most characteristic pathological manifestation of the disease [10]. The fibrosis is especially prominent in the diffuse cutaneous form of SSc, where excessive connective tissue accumulation is due to overproduction of the extracellular matrix by fibroblasts and myofibroblasts, activated by soluble factors such as transforming growth factor beta (TGF- $\beta$ ) [22-26] and connective tissue growth factor [27]. Myofibroblasts are a differentiated and activated form of fibroblast which have been shown to persist in SSc fibroblast cultures and are responsible for increased collagen synthesis and deposition. The molecular mechanisms underlying the origin of the myofibroblast are complex; however, they play a crucial role in wound healing and the development of fibrosis [28, 29]. The fibrotic process is most prominent in the skin, lungs, heart, gastrointestinal tract, kidney, tendons and ligaments, and endocrine glands; widespread perivascular fibrosis also occurs. Fibrotic damage to these affected organs accounts for much of the morbidity and mortality associated with SSc.

The scleroderma phenotype at the cellular level has also been shown to be characterized by oxidative stress, an imbalance between the elevated level of ROS and/or the impaired function of the antioxidant defence system [30]. ROS usually include $\mathrm{O}_{2}{ }^{-}$, hydrogen peroxide $\left(\mathrm{H}_{2} \mathrm{O}_{2}\right)$, hydroxyl radicals $(\cdot \mathrm{OH})$, and $\mathrm{ONOO}^{-}$. The sources of oxidative stress in SSc are complex and interactive and likely to be due to ischaemic-reperfusion injury, dysregulated metabolism of the free radical NO [2-5], and generation of ROS by fibroblasts [6] and activated leukocytes such as monocytes via the NADPH oxidase system [31]. ROS have been demonstrated to be cell transducers of fibroblast proliferation [6], collagen-gene expression, and myofibroblast phenotype conversion in SSc $[6,8,21]$. During the 1990 s-early 2000s clear evidence for oxidative stress in SSc emerged by the enhanced oxidation of lipids and lipoproteins (oxLDL) [32, 33], increased isoprostane production [3437], and also the presence of modified, nitrated proteins in the plasma and skin $[4,7]$. In SSc what is less certain is the exact stage at which increases in free radicals and other reactive species occur, the potential counteractive role of the antioxidant defence system or how both elements are linked to the main events of the disease such as the vascular abnormalities, and the increased synthesis of extracellular matrix, leading to fibrosis. Early studies demonstrated that there is reduced antioxidant capacity in SSc; plasma ascorbic acid (vitamin $\mathrm{C}$ ), $\alpha$-tocopherol, $\beta$-carotene, and selenium were found to be lower in patients than in controls [30, 32,38 . Additionally, the beneficial effects of the antioxidant probucol in patients with Raynaud's phenomenon, a vascular pathology which is associated with SSc, have been shown [39]. Subsequently, antioxidant therapy was proposed as a possible treatment in SSc $[30,38,39]$ and also in other diseases $[40,41]$ with the focus being on the antioxidants counteracting the ROS-induced endothelial damage and vasculopathy that occur. More recently, natural antioxidants such as polyphenols from green tea (Camellia sinensis) extracts, a popular beverage consumed worldwide, have attracted attention due to their potent antioxidant effects, particularly that of one component, (-)-epigallocatechin-3gallate (EGCG). In this paper, we will discuss findings about the mechanisms of NO-mediated modulation of fibrosis as well as evidence suggesting that the dietary antioxidant EGCG could be a therapeutic target for SSc.

\section{Nitric Oxide as a Regulator of the Fibrogenic Response.}

The versatile free radical NO has been implicated in the pathogenesis of SSc. In most biological situations $\mathrm{NO}$ is largely oxidized to nitrate $\left(\mathrm{NO}_{3}{ }^{-}\right)$and nitrite $\left(\mathrm{NO}_{2}{ }^{-}\right)$, with the measurement of total nitrate and nitrite $\mathrm{NO}_{(x)}$ production, as well as ADMA levels, seen as a reflection of endothelial dysfunction in many diseases [1, 9, 42]. Early studies involving $\mathrm{NO}_{(x)}$ production in SSc have shown conflicting results $[2,3,5,43,44]$; however, the discrepancy in these results could be explained by differences in the degree of inflammatory disorder, disease subset, and treatment of the patients. Furthermore, modifications in the dietary $\mathrm{NO}_{(x)}$ intake were not attempted in many of these studies. Later on other groups [2, 4, 5, 45, 46] demonstrated evidence implicating overproduction of $\mathrm{NO}$, with increased plasma $\mathrm{NO}_{3}{ }^{-} / \mathrm{NO}_{2}{ }^{-}$levels, together with elevated nitration of plasma proteins, a marker of $\mathrm{ONOO}^{-}$production [4]. Nitrated proteins $[47,48]$ are also found in the skin in SSc associated with sites of inflammation [3, 4]. There is a growing literature showing strong tissue localization of nitrotyrosine staining or increased levels of free and proteinbound nitrotyrosine in inflammatory diseases. For example, strong staining of nitrotyrosine has been found in lung sections from patients with lung injury [49], while significant amounts of 3-nitrotyrosine have been reported from patients with rheumatoid arthritis [50] and chronic renal failure $[51,52]$.

Interestingly, in SSc there is the paradoxical situation in which NO production by eNOS in endothelial cells is decreased possibly due to the rapid reaction of $\mathrm{NO}$ and $\mathrm{O}_{2}{ }^{-}$to generate the reactive intermediate $\mathrm{ONOO}^{-}$ $[53,54]$ or due to the presence in the circulation of natural inhibitors of NOS activity such as ADMA $[9,42]$ (Figure 1). Therefore, in SSc reduced eNOS expression and microcirculatory dysfunction are in part contributory to the 


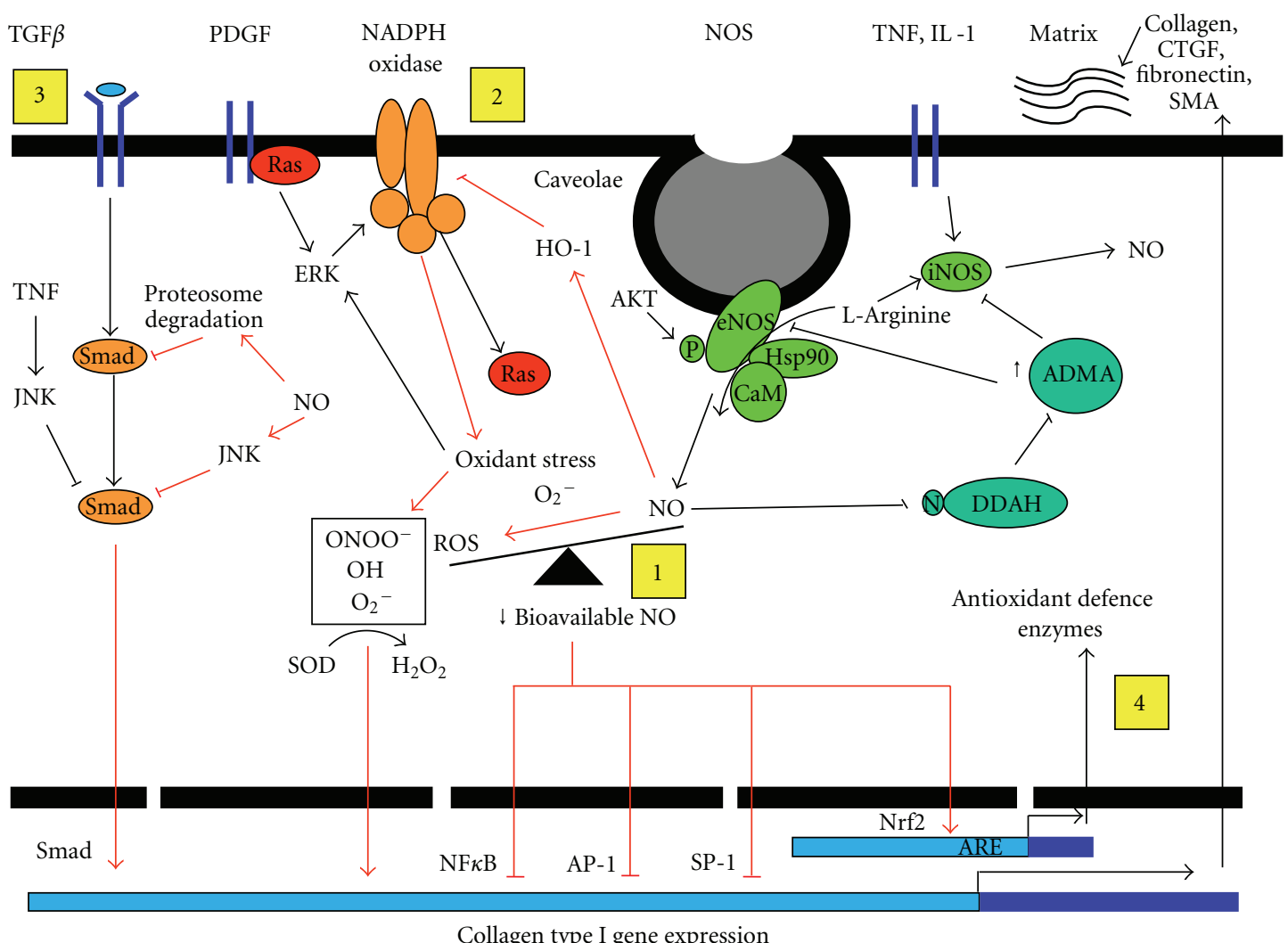

FIGURE 1: Schematic diagram depicting the possible pathways in which NO modulates collagen type I gene expression to affect fibrosis. In the first hypothesis (1), the rapid reaction between $\mathrm{NO}$ and $\mathrm{O}_{2}{ }^{-{ }^{-}}$leads to decreased $\mathrm{NO}$ bioavailability. NO regulation by ADMA may also occur. NO normally can directly activate transcription factors such as NF $\kappa$ B, SP-1, and AP-1 to inhibit collagen gene expression. The second possibility (2) is that $\mathrm{NO}$ normally by activating the protective stress enzyme HO-1 can negatively modulate the NADPH oxidase pathway. In fibrosis, activation of the NADPH oxidase pathway has been shown to increase collagen synthesis and myofibroblast differentiation. The third plausible pathway (3) is that there is signalling crosstalk following TGF- $\beta$ binding to a receptor. Signal pathways potentially important here include the MAP kinase JNK. This would synergise with the Smad signalling pathway and decrease the activation of downstream TGF$\beta$-dependent genes. Alternatively, NO could enhance the proteasomal degradation of SMAD. In the fourth pathway (4), NO indirectly exerts its effects by modulating oxidative stress through upregulation of antioxidant/redox defence genes such as Nrf2 leading to regulation of the extracellular matrix.

associated Raynaud's Phenomenon that is well described in these patients [3, 14-16, 55]. In contrast at inflammatory sites the formation of NO, by iNOS, and $\mathrm{O}_{2}{ }^{-}$are increased by the presence of inflammatory cells such as macrophages or activated fibroblasts [56]. Immunohistological studies of scleroderma skin also show that, as the disease progresses to the later fibrotic stages, the production of eNOS is downregulated, while iNOS is upregulated [3]. Furthermore, studies suggest that under conditions when $\mathrm{NO}$ overproduction occurs, S-nitrosylation of the ADMA regulating enzyme dimethylarginine dimethylaminohydrolase (DDAH) diminishes DDAH activity, leading to an accumulation of ADMA. Subsequently, NOS inhibition as a type of regulatory feedback mechanism may result [57] (Figure 1). Indeed, there is further evidence to indicate increased circulatory levels of ADMA in the serum of diffuse SSc patients, suggesting an NOS regulatory mechanism later on in the disease [4].

NO has also been reported to act as an antifibrotic effector in animal models of experimental fibrosis $[58,59]$. For example, in a murine model of pulmonary fibrosis, a loss of NO bioactivity, in eNOS knock-out mice, resulted in prolonged fibrosis [58]. Furthermore, another study also demonstrated that overexpressing eNOS, using transgenic mice, reduced fibrotic content after bleomycin-induced fibrosis [59]. In rats, the long-term inhibition of the inducible form of NOS (iNOS) has also been shown to favour the development of fibrosis [60]. Additional studies assessing NO metabolism in the tight-skin $1\left(\right.$ Tsk- $\left.-1 /^{+}\right)$mouse, which is predisposed to SSc and often used as an experimental animal model for fibrosis, reported that while type I collagen protein expression was elevated in Tsk- $1 /^{+}$skin tissue, eNOS protein and gene expressions were reduced compared to wild-type controls [61]. Furthermore, there was decreased NOS activity in Tsk-1/ ${ }^{+}$skin tissue [61]. Correspondingly, the protective antioxidant enzyme haemoxygenase-1 (HO1) and the associated transcription factor nuclear factor erythroid-2-related factor 2 (Nrf2) showed reduced protein and gene expression levels in Tsk- $1 /^{+}$skin, while there was also less total antioxidant activity [61]. The findings suggested that there was also abnormal NO metabolism in 
the Tsk- $1 /^{+}$mouse, particularly in the skin, while expression and activity of protective antioxidants were reduced.

Several studies have gained insights into the intracellular mechanisms by which NO might further modulate a fibrotic phenotype. Nitric oxide can induce HO-1, which is also induced by a variety of cellular stress, including free-radicalmediated stresses and oxygen deprivation [62]. HO-1 in turn can also increase oxidative-stress-related transcription factors such as Nrf2. Because of high similarity between the Nrf2-binding sequence (NF-E2 motif) and the antioxidant response element (ARE) in regulatory regions of several phase 2 antioxidant enzymes, Nrf2 is a putative mediator of ARE responses. Consequently, other ARE-bearing protective phase 2 antioxidant/redox enzymes such as glutathione peroxidase, and classical antioxidant enzymes such as superoxide dismutase [SOD] and catalase as well as HO-1 induce Nrf2 gene expression (Figure 1). There is a large body of evidence suggesting that $\mathrm{HO}-1$ is a cytoprotective enzyme, and its induction in the setting of increased cellular stresses helps maintain physiological homeostasis [63]. Thus, embryonic fibroblasts derived from $\mathrm{HO}-1^{-/-}$knock-out mice are significantly less resistant to the cytotoxicity induced by $\mathrm{H}_{2} \mathrm{O}_{2}$ and paraquat than wildtype controls $[64,65]$. Conversely, cells overexpressing HO1 have been reported to be more resistant to oxidantinduced toxicity than controls [64]. Indeed, other groups which examined $\mathrm{Nrf} 2^{-/-}$knock-out mice reported increased bleomycin-induced pulmonary fibrosis [66] and expression of extracellular matrix genes such as collagens after hyperoxic exposure [67] when compared to wild-type controls. It has, thus, been suggested that an increased oxidative burden by suppression of antioxidant defence mechanisms in $\mathrm{Nrf} 2^{-/-}$ mice secondarily triggers regulation of extracellular matrix genes for repair responses [67]. Interestingly, recently studies in SSc have also suggested Nrf2 as a target for antifibrotic therapy [68].

Other studies suggest that NO influences fibrosis through modulatory effects on the TGF- $\beta$ pathway [69-71], initiation of fibroblast apoptosis and myofibroblast differentiation $[60,72,73]$, and/or neutralization of profibrotic ROS [53, 54] (Figure 1). Additionally, NO can modulate collagen synthesis; however, at present, the mechanisms and signalling pathways of NO-mediated inhibition of collagen are not clear. NO inhibition of collagen in dermal SSc fibroblasts has been reported to be by cGMP-independent regulatory mechanisms and in part may be due to up-regulation of matrix metalloproteinase-1 (MMP-1, an essential collagenase involved in collagen degradation) protein and activity levels and/or inhibition of prolyl hydroxylase activity (an enzyme important in the posttranslational processing of collagen) [74]. Similarly, further evidence has also confirmed a role for NO in regulation of the extracellular matrix in other fibrotic diseases and cell types [70, 73, 75-80]. It was initially discovered in vascular smooth muscle cells [77, 78] and in mesangial cells $[70,80]$. Recently, this downregulation has also been found in human dermal $[69,74]$, intestinal [81], and rat cardiac [76] fibroblast cells. From the view of the signalling pathway, it has been shown that $\mathrm{NO}$ downregulation of collagen synthesis in other cell types can occur in a cGMP-dependent $[69,76]$ or independent manner even though addition of NO could increase intracellular levels of cGMP [75, 82]. Furthermore other investigators using rat mesangial cells show that it is possible that the suppression of collagen synthesis by NO could involve an increase in MMP production and activity [80, 83]. Indeed, NO regulation of prolyl hydroxylase has been postulated in lapine articular chondrocytes [75]. Prolyl hydroxylase catalyses the formation of 4-hydroxyproline in collagens by hydroxylation of proline, and the reaction, in particular, requires $\mathrm{Fe}^{2+}$ and ascorbate and generates free radicals, all of which are sensitive to NO [84]. Under-hydroxylated procollagens do not form stable triple helices at body temperature and, thus, remain partially unfolded, where they are presumably more susceptible to degradation by intracellular collagenases. An additional number of intracellular targets for NO have been described [85], including $\mathrm{NO}$ regulation of NADPH oxidase [86], MAP kinases (e.g., JNK, ERK) [87], SMADs [71], and transcription factors (e.g., NF $\kappa$ B, AP-1, SP-1) [88] which are key signalling pathways of fibroblast proliferation and collagen gene expression $[6,8,25,89,90]$ (Figure 1). Taken together these studies strongly suggest a definitive link between NO expression and modulation of fibrosis.

\section{Antioxidants, (-)-Epigallocatechin-3-Gallate, and Systemic Sclerosis}

In systemic sclerosis clear evidence for oxidative stress has been shown by increased levels of $\mathrm{O}_{2}{ }^{--}$[6], antibodies against oxLDL [91], enhanced lipid peroxidation [32, 33], increased F2-isoprostanes [35-37], and increased circulatory levels of nitrotyrosine [4, 7]. Additionally, ROS-induced endothelial damage occurs as well as the underlying vasculopathy associated with SSc known as Raynaud's Phenomenon. Raynaud's Phenomenon is characterised by transient attacks of cold-induced digital ischaemia associated with intense vasospasm in the fingers $[55,92,93]$. It occurs as a primary condition and as secondary to SSc. Currently, the underlying disorder of Raynaud's Phenomenon is thought to be related to the abnormal regulation of peripheral vascular tone at the level of the digital microcirculation [55, 92, 93]. Although nearly all patients with SSc exhibit Raynaud's Phenomenon, it is still uncertain whether their pathogenesis is identical to patients with Raynaud's Phenomenon alone. Furthermore, in SSc, it is not only the digital and peripheral vessels that exhibit vasospasm but also the vessels of the internal organs [13]. The pathophysiology underlying the coldinduced vasospasm characteristic of Raynaud's Phenomenon remains confused [55, 92]. Initially, it was suggested that $\alpha_{2}$-adrenoceptors accounted for the supersensitivity [94]. Further studies found that $\alpha_{1}$-adrenoceptors appears to predominate in the physiological control of cold-induced digital vasoconstriction whereas both $\alpha_{1}$ - and $\alpha_{2}$-adrenoceptors play an equal role in Raynaud's subjects [15]. However, selective antagonism of these receptor subtypes in both normal and Raynaud's subjects did not abolish vasoconstriction suggesting that nonadrenergic mechanisms may also 
contribute to this response. Other studies in the dorsal hand vein [95], digital arteries [96], as well as isolated gluteal subcutaneous resistance arteries [97] of primary Raynaud's subjects show an impairment of endothelium-dependent relaxation.

Although the vasospastic condition in Raynaud's Phenomenon may arise as a result of a functional disturbance at the level of the vessel wall, it is possible that circulating factors in the blood that alter the release of endothelial cell mediators, such as prostacyclin, NO, endothelin, or increase ROS and oxidative stress may contribute to the disease [93]. Early clinical trials, however, indicate limited success in treatment of patients with Raynaud's Phenomenon secondary to SSc with antioxidants such as $\alpha$-tocopherol or vitamin $\mathrm{C}$, which did not decrease urinary markers of oxidative stress such as $\mathrm{F}(2)$-isoprostanes nor improved microvascular perfusion after cold exposure $[98,99]$. More hopeful has been the use of the potent antioxidant $\mathrm{N}$ acetylcysteine which has been shown to improve the vascular symptoms of Raynaud's Phenomenon in patients with SSc $[100,101]$. The type of antioxidant used, phase of the disease, and duration of use may be key factors in successful treatment therapies involving antioxidants in both SSc and the associated Raynaud's Phenomenon.

Natural antioxidants, such as polyphenols from green tea extracts, are now being considered and investigated in particular (-)-epigallocatechin-3-gallate (EGCG). Other less active polyphenol constituents of green tea are believed to be (-)-epigallocatechin (EGC), (-)-epicatechin (EC), and (-)epicatechin-3-gallate (ECG). The prominent antioxidant effects of EGCG derive from the phenol rings that can act as electron traps to scavenge free radicals, inhibit the formation of ROS such as $\mathrm{O}_{2}{ }^{--}$and $\mathrm{ONOO}^{-}$, and reduce oxidative stress $[102,103]$. EGCG has a higher potent antioxidant capability than $\alpha$-tocopherol or vitamin C [104], and has been demonstrated to be an effective inhibitor of oxidativestress-induced protein tyrosine nitration during isolation of platelets $[48,105]$.

Studies have also shown that EGCG may directly inhibit molecular targets and regulate multiple signal transduction pathways such as MAP kinases (PI3-kinase, ERK) and transcription factors (Nrf2, NF- $\kappa \mathrm{B}, \mathrm{AP}-1)$ and/or induce antioxidant enzymes such as HO-1 [106, 107]. In addition to its antioxidant properties, it has been shown to possess antifibrotic, anticancer, and anti-inflammatory activities regulating both TGF- $\beta$ and PDGF-induced $\alpha 1$ (I) collagen, fibronectin, $\alpha$-smooth muscle actin ( $\alpha$-SMA), and proliferation in activated human and rat hepatic stellate cells [108$110]$, rat pancreatic cells $[111,112]$, human keloid fibroblasts [113], and SSc dermal fibroblasts [114]. Additionally, EGCG can counteract TGF $\beta$-induced ROS in human dermal fibroblasts from healthy controls, SSc patients, and in a dermal fibroblast cell line, indicating its potential effectiveness as an antioxidant to reduce oxidant stress in the disease scleroderma [114]. Interestingly, other studies have shown data that EGCG can beneficially inhibit ROS through attenuating NADPH oxidase expression $[115,116]$. Furthermore, topical administration of EGCG has successfully been shown to inhibit ultraviolet radiation-induced oxidative stress and tumorigenesis in human and animal skin models $[117,118]$. Particularly useful will also be animal models of fibrosis where recently, in the case of bleomycin-induced pulmonary fibrosis and carbon tetrachloride-induced hepatic fibrosis, EGCG has been promisingly shown to exert anti-fibrotic effects [119-121].

In summary, it is clear that further studies are needed to delineate the key NO-mediated signal transduction and transcription pathways that facilitate type I collagen production and fibrosis in the disease scleroderma. Studies such as these will help define key targets and candidates for therapy. Furthermore the dietary antioxidant EGCG, with its long history of safe beverage consumption in green tea together with its demonstrated potent antioxidant capability, is a good candidate for therapeutic treatment targeting oxidative stress and fibrogenesis in patients with SSc. Further clinical studies, to confirm its efficacy, determine optimal dosage and duration of use, and treatment indicators are required.

\section{References}

[1] R. Bruckdorfer, "The basics about nitric oxide," Molecular Aspects of Medicine, vol. 26, no. 1-2, pp. 3-31, 2005.

[2] G. N. Andersen, K. Caidahl, E. Kazzam et al., "Correlation between increased nitric oxide production and markers of endothelial activation in systemic sclerosis: findings with the soluble adhesion molecules e-selectin, intercellular adhesion molecule 1, and vascular cell adhesion molecule 1," Arthritis and Rheumatism, vol. 43, no. 5, pp. 1085-1093, 2000.

[3] S. A. Cotton, A. L. Herrick, M. I. V. Jayson, and A. J. Freemont, "Endothelial expression of nitric oxide synthases and nitrotyrosine in systemic sclerosis skin," Journal of Pathology, vol. 189, no. 2, pp. 273-278, 1999.

[4] A. Dooley, B. Gao, N. Bradley et al., "Abnormal nitric oxide metabolism in systemic sclerosis: increased levels of nitrated proteins and asymmetric dimethylarginine," Rheumatology, vol. 45, no. 6, pp. 676-684, 2006.

[5] T. Yamamoto, I. Katayama, and K. Nishioka, "Nitric oxide production and inducible nitric oxide synthase expression in systemic sclerosis," Journal of Rheumatology, vol. 25, no. 2, pp. 314-317, 1998.

[6] P. Sambo, S. S. Baroni, M. Luchetti et al., "Oxidative stress in scleroderma: maintenance of scleroderma fibroblast phenotype by the constitutive up-regulation of reactive oxygen species generation through the NADPH oxidase complex pathway," Arthritis and Rheumatism, vol. 44, no. 11, pp. 2653-2664, 2001.

[7] K. Shimizu, F. Ogawa, E. Muroi et al., "Increased serum levels of nitrotyrosine, a marker for peroxynitrite production, in systemic sclerosis," Clinical and Experimental Rheumatology, vol. 25, no. 2, pp. 281-286, 2007.

[8] S. Svegliati, R. Cancello, P. Sambo et al., "Platelet-derived growth factor and reactive oxygen species (ROS) regulate Ras protein levels in primary human fibroblasts via ERK1/2: amplification of ROS and Ras in systemic sclerosis fibroblasts," Journal of Biological Chemistry, vol. 280, no. 43, pp. 36474-36482, 2005.

[9] R. H. Böger, P. Vallance, and J. P. Cooke, "Asymmetric dimethylarginine (ADMA): a key regulator of nitric oxide synthase," Atherosclerosis Supplements, vol. 4, no. 4, pp. 1-3, 2003. 
[10] C. P. Denton, C. M. Black, and D. J. Abraham, "Mechanisms and consequences of fibrosis in systemic sclerosis," Nature Clinical Practice Rheumatology, vol. 2, no. 3, pp. 134-144, 2006.

[11] C. T. Derk and S. A. Jimenez, "Systemic sclerosis: current views of its pathogenesis," Autoimmunity Reviews, vol. 2, no. 4, pp. 181-191, 2003.

[12] J. Varga and D. Abraham, "Systemic sclerosis: a prototypic multisystem fibrotic disorder," Journal of Clinical Investigation, vol. 117, no. 3, pp. 557-567, 2007.

[13] C. M. Black and C. P. Denton, "Scleroderma and related disorders in adults and children," in Oxford Textbook of Rheumatology, P. J. Maddison, D. A. Isenberg, P. Woo, and D. N. Glass, Eds., pp. 1217-1247, Oxford University Press, New York, NY, USA, 2nd edition, 1998.

[14] R. J. Prescott, A. J. Freemont, C. J. P. Jones, J. Hoyland, and P. Fielding, "Sequential dermal microvascular and perivascular changes in the development of scleroderma," Journal of Pathology, vol. 166, no. 3, pp. 255-263, 1992.

[15] R. R. Freedman, R. Girgis, and M. D. Mayes, "Endothelial and adrenergic dysfunction in Raynaud's phenomenon and scleroderma," Journal of Rheumatology, vol. 26, no. 11, pp. 2386-2388, 1999.

[16] A. J. Freemont, J. Hoyland, P. Fielding, N. Hodson, and M. I. V. Jayson, "Studies of the microvascular endothelium in uninvolved skin of patients with systemic sclerosis: direct evidence for a generalized microangiopathy," British Journal of Dermatology, vol. 126, no. 6, pp. 561-568, 1992.

[17] R. Sgonc, M. S. Gruschwitz, G. Boeck, N. Sepp, J. Gruber, and G. Wick, "Endothelial cell apoptosis in systemic sclerosis is induced by antibody-dependent cell-mediated cytotoxicity via CD95," Arthritis and Rheumatism, vol. 43, no. 11, pp. 2550-2562, 2000.

[18] M. B. Kahaleh, "Endothelin, an endothelial-dependent vasoconstrictor in scleroderma: enhanced production and profibrotic action," Arthritis and Rheumatism, vol. 34, no. 8, pp. 978-983, 1991.

[19] C. P. Denton, M. C. M. Bickerstaff, X. Shiwen et al., "Serial circulating adhesion molecule levels reflect disease severity in systemic sclerosis," British Journal of Rheumatology, vol. 34, no. 11, pp. 1048-1054, 1995.

[20] A. Pignone, C. Scaletti, M. Matucci-Cerinic et al., "Antiendothelial cell antibodies in systemic sclerosis: significant association with vascular involvement and alveolo-capillary impairment," Clinical and Experimental Rheumatology, vol. 16, no. 5, pp. 527-532, 1998.

[21] S. S. Baroni, M. Santillo, F. Bevilacqua et al., "Stimulatory autoantibodies to the PDGF receptor in systemic sclerosis," New England Journal of Medicine, vol. 354, no. 25, pp. 26672676, 2006.

[22] Y. Chen, S. W. Xu, J. van Beek et al., "Matrix contraction by dermal fibroblasts requires transforming growth factor$\beta$ /activin-linked kinase 5 , heparan sulfate-containing proteoglycans, and MEK/ERK: insights into pathological scarring in chronic fibrotic disease," American Journal of Pathology, vol. 167, no. 6, pp. 1699-1711, 2005.

[23] Y. Chen, S. W. Xu, M. Eastwood et al., "Contribution of activin receptor-like kinase 5 (transforming growth factor $\beta$ receptor type I) signaling to the fibrotic phenotype of scleroderma fibroblasts," Arthritis and Rheumatism, vol. 54, no. 4, pp. 1309-1316, 2006.

[24] G. Lakos, S. Takagawa, S. J. Chen et al., “Targeted disruption of TGF- $\beta /$ Smad3 signaling modulates skin fibrosis in a mouse model of scleroderma," American Journal of Pathology, vol. 165, no. 1, pp. 203-217, 2004.

[25] A. Leask and D. J. Abraham, "TGF- $\beta$ signaling and the fibrotic response," FASEB Journal, vol. 18, no. 7, pp. 816-827, 2004.

[26] S. Liu, X. Shi-Wen, L. Kennedy et al., "FAK is required for TGF $\beta$-induced JNK phosphorylation in fibroblasts: implications for acquisition of a matrix-remodeling phenotype," Molecular Biology of the Cell, vol. 18, no. 6, pp. 2169-2178, 2007.

[27] C. Fonseca, G. E. Lindahl, M. Ponticos et al., "A polymorphism in the CTGF promoter region associated with systemic sclerosis," New England Journal of Medicine, vol. 357, no. 12, pp. 1210-1220, 2007.

[28] B. Hinz, S. H. Phan, V. J. Thannickal, A. Galli, M. L. Bochaton-Piallat, and G. Gabbiani, "The myofibroblast: one function, multiple origins," American Journal of Pathology, vol. 170, no. 6, pp. 1807-1816, 2007.

[29] D. J. Abraham, B. Eckes, V. Rajkumar, and T. Krieg, "New developments in fibroblast and myofibroblast biology: implications for fibrosis and scleroderma," Current Rheumatology Reports, vol. 9, no. 2, pp. 136-143, 2007.

[30] A. L. Herrick and M. Matucci Cerinic, "The emerging problem of oxidative stress and the role of antioxidants in systemic sclerosis," Clinical and Experimental Rheumatology, vol. 19, no. 1, pp. 4-8, 2001.

[31] P. Sambo, L. Jannino, M. Candela et al., "Monocytes of patients with systemic sclerosis (scleroderma) spontaneously release in vitro increased amounts of superoxide anion," Journal of Investigative Dermatology, vol. 112, no. 1, pp. 7884, 1999.

[32] K. R. Bruckdorfer, J. B. Hillary, T. Bunce, R. Vancheeswaran, and C. M. Black, "Increased susceptibility to oxidation of low-density lipoproteins isolated from patients with systemic sclerosis," Arthritis and Rheumatism, vol. 38, no. 8, pp. 10601067, 1995.

[33] M. Tikly, K. Channa, P. Theodorou, and M. Gulumian, "Lipid peroxidation and trace elements in systemic sclerosis," Clinical Rheumatology, vol. 25, no. 3, pp. 320-324, 2006.

[34] L. Casciola-Rosen, F. Wigley, and A. Rosen, "Scleroderma autoantigens are uniquely fragmented by metal-catalyzed oxidation reactions: implications for pathogenesis," Journal of Experimental Medicine, vol. 185, no. 1, pp. 71-79, 1997.

[35] J. L. Cracowski, P. H. Carpentier, B. Imbert et al., "Increased urinary F2-isoprostanes in systemic sclerosis, but not in primary Raynaud's phenomenon: effect of cold exposure," Arthritis and Rheumatism, vol. 46, no. 5, pp. 1319-1323, 2002.

[36] C. M. Stein, S. B. Tanner, J. A. Awad, L. J. Roberts, and J. D. Morrow, "Evidence of free radical-mediated injury (isoprostane overproduction) in scleroderma," Arthritis and Rheumatism, vol. 39, no. 7, pp. 1146-1150, 1996.

[37] F. Ogawa, K. Shimizu, E. Muroi et al., "Serum levels of 8 -isoprostane, a marker of oxidative stress, are elevated in patients with systemic sclerosis," Rheumatology, vol. 45, no. 7, pp. 815-818, 2006.

[38] S. Gabriele, P. Alberto, G. Sergio, F. Fernanda, and M. C. Marco, "Emerging potentials for an antioxidant therapy as a new approach to the treatment of systemic sclerosis," Toxicology, vol. 155, no. 1-3, pp. 1-15, 2000.

[39] C. P. Denton, T. D. Bunce, M. B. Dorado et al., "Probucol improves symptoms and reduces lipoprotein oxidation susceptibility in patients with Raynaud's phenomenon," Rheumatology, vol. 38, no. 4, pp. 309-315, 1999. 
[40] D. A. Lawlor, G. D. Smith, D. Kundu, K. R. Bruckdorfer, and S. Ebrahim, "Those confounded vitamins: what can we learn from the differences between observational versus randomised trial evidence?" Lancet, vol. 363, no. 9422, pp. 1724-1727, 2004.

[41] K. R. Bruckdorfer, "Antioxidants and CVD," Proceedings of the Nutrition Society, vol. 67, no. 2, pp. 214-222, 2008.

[42] P. Vallance and J. Leiper, "Cardiovascular biology of the asymmetric dimethylarginine:dimethylarginine dimethylaminohydrolase pathway," Arteriosclerosis, Thrombosis, and Vascular Biology, vol. 24, no. 6, pp. 1023-1030, 2004.

[43] B. Kahaleh and P. S. Fan, "Down regulation of nitric oxide synthase gene in microvascular endothelial cells from lesional scleroderma: assessment by quantitative RT-PCR and possible role for cytoxic T-cells," Arthritis and Rheumatism, vol. 41, supplement 9, p. S277, 1998.

[44] B. Kahaleh, P. S. Fan, M. Matucci-Cerinic, M. StefanovicRacic, and L. Ignarro, "Study of endothelial dependent relaxation in scleroderma," Arthritis and Rheumatism, vol. 36, supplement 9, p. S180, 1993.

[45] A. Sud, M. Khullar, A. Wanchu, and P. Bambery, "Increased nitric oxide production in patients with systemic sclerosis," Nitric Oxide-Biology and Chemistry, vol. 4, no. 6, pp. 615619, 2000.

[46] K. Takagi, Y. Kawaguchi, M. Hara, T. Sugiura, M. Harigai, and N. Kamatani, "Serum nitric oxide (NO) levels in systemic sclerosis patients: correlation between NO levels and clinical features," Clinical and Experimental Immunology, vol. 134, no. 3, pp. 538-544, 2003.

[47] S. Y. Low, M. Sabetkar, K. R. Bruckdorfer, and K. M. Naseem, "The role of protein nitration in the inhibition of platelet activation by peroxynitrite," FEBS Letters, vol. 511, no. 1-3, pp. 59-64, 2002.

[48] M. Sabetkar, S. Y. Low, K. M. Naseem, and K. R. Bruckdorfer, "The nitration of proteins in platelets: significance in platelet function," Free Radical Biology and Medicine, vol. 33, no. 6, pp. 728-736, 2002.

[49] N. W. Kooy, J. A. Royall, Y. Z. Ye, D. R. Kelly, and J. S. Beckman, "Evidence for in vivo peroxynitrite production in human acute lung injury," American Journal of Respiratory and Critical Care Medicine, vol. 151, no. 4, pp. 1250-1254, 1995.

[50] P. I. Mapp, R. Klocke, D. A. Walsh et al., "Localization of 3nitrotyrosine to rheumatoid and normal synovium," Arthritis and Rheumatism, vol. 44, no. 7, pp. 1534-1539, 2001.

[51] K. Bennett-Richards, N. J. Bradley, D. Kundu, J. E. Deanfield, L. Rees, and K. R. A. Bruckdorfer, "A marked increase in plasma nitrated proteins in children with chronic renal failure," Nitric Oxide-Biology and Chemistry, pp. 238-239, 2000.

[52] N. Fukuyama, Y. Takebayashi, M. Hida, H. Ishida, K. Ichimori, and H. Nakazawa, "Clinical evidence of peroxynitrite formation in chronic renal failure patients with septic shock," Free Radical Biology and Medicine, vol. 22, no. 5, pp. 771-774, 1997.

[53] H. Cai and D. G. Harrison, "Endothelial dysfunction in cardiovascular diseases: the role of oxidant stress," Circulation Research, vol. 87, no. 10, pp. 840-844, 2000.

[54] J. S. Beckman and W. H. Koppenol, "Nitric oxide, superoxide, and peroxynitrite: the good, the bad, and the ugly," American Journal of Physiology_Cell Physiology, vol. 271, no. 5, part 1, pp. C1424-C1437, 1996.

[55] A. L. Herrick, "Pathogenesis of Raynaud's phenomenon," Rheumatology, vol. 44, no. 5, pp. 587-596, 2005.
[56] M. Matucci Cerinic and M. B. Kahaleh, "Beauty and the beast. The nitric oxide paradox in systemic sclerosis," Rheumatology, vol. 41, no. 8, pp. 843-847, 2002.

[57] J. Leiper, J. Murray-Rust, N. McDonald, and P. Vallance, "Snitrosylation of dimethylarginine dimethylaminohydrolase regulates enzyme activity: further interactions between nitric oxide synthase and dimethylarginine dimethylaminohydrolase," Proceedings of the National Academy of Sciences of the United States of America, vol. 99, no. 21, pp. 13527-13532, 2002.

[58] M. P. Chung, M. M. Monick, N. Y. Hamzeh, N. S. Butler, L. S. Powers, and G. W. Hunninghake, "Role of repeated lung injury and genetic background in bleomycin-induced fibrosis," American Journal of Respiratory Cell and Molecular Biology, vol. 29, no. 3, part 1, pp. 375-380, 2003.

[59] S. Yoshimura, Y. Nishimura, T. Nishiuma, T. Yamashita, K. Kobayashi, and M. Yokoyama, "Overexpression of nitric oxide synthase by the endothelium attenuates bleomycin-induced lung fibrosis and impairs MMP-9/TIMP-1 balance," Respirology, vol. 11, no. 5, pp. 546-556, 2006.

[60] M. G. Ferrini, D. Vernet, T. R. Magee et al., "Antifibrotic role of inducible nitric oxide synthase," Nitric Oxide-Biology and Chemistry, vol. 6, no. 3, pp. 283-294, 2002.

[61] A. Dooley, S. Y. Low, A. Holmes et al., "Nitric oxide synthase expression and activity in the tight-skin mouse model of fibrosis," Rheumatology, vol. 47, no. 3, pp. 272-280, 2008.

[62] R. Motterlini, R. Foresti, M. Intaglietta, and R. M. Winslow, "NO-mediated activation of heme oxygenase: endogenous cytoprotection against oxidative stress to endothelium," American Journal of Physiology-Heart and Circulatory Physiology, vol. 270, no. 1, part 2, pp. H107-H114, 1996.

[63] R. Stocker and M. A. Perrella, "Heme oxygenase-1: a novel drug target for atherosclerotic diseases?" Circulation, vol. 114, no. 20, pp. 2178-2189, 2006.

[64] R. Hori, M. Kashiba, T. Toma et al., "Gene transfection of H25A mutant heme oxygenase-1 protects cells against hydroperoxide-induced cytotoxicity," Journal of Biological Chemistry, vol. 277, no. 12, pp. 10712-10718, 2002.

[65] K. D. Poss and S. Tonegawa, "Reduced stress defense in heme oxygenase 1-deficient cells," Proceedings of the National Academy of Sciences of the United States of America, vol. 94, no. 20, pp. 10925-10930, 1997.

[66] H. Y. Cho, S. P. M. Reddy, M. Yamamoto, and S. R. Kleeberger, "The transcription factor NRF2 protects against pulmonary fibrosis," FASEB Journal, vol. 18, no. 11, pp. 12581260, 2004.

[67] H. Y. Cho, S. P. Reddy, A. DeBiase, M. Yamamoto, and S. R. Kleeberger, "Gene expression profiling of NRF2-mediated protection against oxidative injury," Free Radical Biology and Medicine, vol. 38, no. 3, pp. 325-343, 2005.

[68] K. Komura, J. Wei, G. Lord, and J. Varga, "The triterpenoid CDDO abrogates canonical TGF-beta signaling and fibrotic responses in normal and scleroderma fibroblasts by stabilizing the anti-oxidant nuclear factor-like 2 (Nrf2)," Arthritis and Rheumatism, vol. 62, supplement 10, p. 617, 2010.

[69] A. J. Chu and J. K. Prasad, "Up-regulation by human recombinant transforming growth factor $\beta-1$ of collagen production in cultured dermal fibroblasts is mediated by the inhibition of nitric oxide signaling," Journal of the American College of Surgeons, vol. 188, no. 3, pp. 271-280, 1999.

[70] P. A. Craven, R. K. Studer, J. Felder, S. Phillips, and F. R. DeRubertis, "Nitric oxide inhibition of transforming growth factor- $\beta$ and collagen synthesis in mesangial cells," Diabetes, vol. 46, no. 4, pp. 671-681, 1997. 
[71] M. Saura, C. Zaragoza, B. Herranz et al., "Nitric oxide regulates transforming growth factor- $\beta$ signaling in endothelial cells," Circulation Research, vol. 97, no. 11, pp. 1115-1123, 2005.

[72] D. Vernet, M. G. Ferrini, E. G. Valente et al., "Effect of nitric oxide on the differentiation of fibroblasts into myofibroblasts in the Peyronie's fibrotic plaque and in its rat model," Nitric Oxide-Biology and Chemistry, vol. 7, no. 4, pp. 262-276, 2002.

[73] E. G. A. Valente, D. Vernet, M. G. Ferrini, A. Qian, J. Rajfer, and N. F. Gonzalez-Cadavid, "L-Arginine and phosphodiesterase (PDE) inhibitors counteract fibrosis in the Peyronie's fibrotic plaque and related fibroblast cultures," Nitric Oxide-Biology and Chemistry, vol. 9, no. 4, pp. 229-244, 2003.

[74] A. Dooley, B. Gao, X. Shi-Wen et al., "Effect of nitric oxide and peroxynitrite on type I collagen synthesis in normal and scleroderma dermal fibroblasts," Free Radical Biology and Medicine, vol. 43, no. 2, pp. 253-264, 2007.

[75] M. Cao, A. Westerhausen-Larson, C. Niyibizi et al., "Nitric oxide inhibits the synthesis of type-II collagen without altering Col2A1 mRNA abundance: prolyl hydroxylase as a possible target," Biochemical Journal, vol. 324, part 1, pp. 305-310, 1997.

[76] N. N. Kim, S. Villegas, S. R. Summerour, and F. J. Villarreal, "Regulation of cardiac fibroblast extracellular matrix production by bradykinin and nitric oxide," Journal of Molecular and Cellular Cardiology, vol. 31, no. 2, pp. 457-466, 1999.

[77] V. Kolpakov, D. Gordon, and T. J. Kulik, "Nitric oxidegenerating compounds inhibit total protein and collagen synthesis in cultured vascular smooth muscle cells," Circulation Research, vol. 76, no. 2, pp. 305-309, 1995.

[78] P. R. Myers and M. A. Tanner, "Vascular endothelial cell regulation of extracellular matrix collagen: role of nitric oxide," Arteriosclerosis, Thrombosis, and Vascular Biology, vol. 18, no. 5, pp. 717-722, 1998.

[79] M. W. Owens, S. A. Milligan, and M. B. Grisham, "Inhibition of pleural mesothelial cell collagen synthesis by nitric oxide," Free Radical Biology and Medicine, vol. 21, no. 5, pp. 601-607, 1996.

[80] H. Trachtman, S. Futterweit, and P. Singhal, "Nitric oxide modulates the synthesis of extracellular matrix proteins in cultured rat mesangial cells," Biochemical and Biophysical Research Communications, vol. 207, no. 1, pp. 120-125, 1995.

[81] D. Chakravortty and K. S. N. Kumar, "Induction of cell proliferation and collagen synthesis in human small intestinal lamina propria fibroblasts by lipopolysaccharide: possible involvement of nitric oxide," Biochemical and Biophysical Research Communications, vol. 240, no. 2, pp. 458-463, 1997.

[82] R. D. Curran, F. K. Ferrari, P. H. Kispert et al., "Nitric oxide and nitric oxide-generating compounds inhibit hepatocyte protein synthesis," FASEB Journal, vol. 5, no. 7, pp. 20852092, 1991.

[83] H. Trachtman, S. Futterweit, P. Garg, K. Reddy, and P. C. Singhal, "Nitric oxide stimulates the activity of a $72 \mathrm{kDa}$ neutral matrix metalloproteinase in cultured rat mesangial cells," Biochemical and Biophysical Research Communications, vol. 218, no. 3, pp. 704-708, 1996.

[84] K. I. Kivirikko, R. Myllylä, and T. Pihlajaniemi, "Protein hydroxylation: prolyl 4-hydroxylase, an enzyme with four cosubstrates and a multifunctional subunit," The FASEB Journal, vol. 3, no. 5, pp. 1609-1617, 1989.
[85] J. Pfeilschifter, W. Eberhardt, and A. Huwiler, "Nitric oxide and mechanisms of redox signalling: matrix and matrixmetabolizing enzymes as prime nitric oxide targets," European Journal of Pharmacology, vol. 429, no. 1-3, pp. 279-286, 2001.

[86] F. Jiang, S. J. Roberts, S. R. Datla, and G. J. Dusting, "NO modulates NADPH oxidase function via heme oxygenase-1 in human endothelial cells," Hypertension, vol. 48, no. 5, pp. 950-957, 2006.

[87] H. Kim, J. Shim, P. L. Han, and E. J. Choi, "Nitric oxide modulates the c-Jun N-terminal kinase/stress-activated protein kinase activity through activating c-Jun $\mathrm{N}$-terminal kinase kinase," Biochemistry, vol. 36, no. 44, pp. 1367713681, 1997.

[88] C. Bogdan, "Nitric oxide and the regulation of gene expression," Trends in Cell Biology, vol. 11, no. 2, pp. 66-75, 2001.

[89] F. Verrecchia, E. F. Wagner, and A. Mauviel, "Distinct involvement of the Jun-N-terminal kinase and NF- $\kappa \mathrm{B}$ pathways in the repression of the human COL1A2 gene by TNF- $\alpha$," EMBO Reports, vol. 3, no. 11, pp. 1069-1074, 2002.

[90] A. K. Ghosh, "Factors involved in the regulation of type I collagen gene expression: implication in fibrosis," Experimental Biology and Medicine, vol. 227, no. 5, pp. 301-314, 2002.

[91] A. L. Herrick, K. J. Illingworth, S. Hollis, J. M. GomezZumaquero, and F. J. Tinahones, "Antibodies against oxidized low-density lipoproteins in systemic sclerosis," Rheumatology, vol. 40, no. 4, pp. 401-405, 2001.

[92] E. P. L. Turton, P. J. Kent, and R. C. Kester, "The aetiology of Raynaud's phenomenon," Cardiovascular Surgery, vol. 6, no. 5, pp. 431-440, 1998.

[93] J. P. Cooke and J. M. Marshall, "Mechanisms of Raynaud's disease," Vascular Medicine, vol. 10, no. 4, pp. 293-307, 2005.

[94] J. P. Cooke, S. J. Creager, K. M. Scales et al., "Role of digital artery adrenoceptors in Raynaud's disease," Vascular Medicine, vol. 2, no. 1, pp. 1-7, 1997.

[95] G. V. Bedarida, D. Kim, T. F. Blaschke, and B. B. Hoffman, "Venodilation in Raynaud's disease," Lancet, vol. 342, no. 8885, pp. 1451-1454, 1993.

[96] S. Singh, J. C. De Trafford, P. A. Baskerville, and J. F. Martin, "Response of digital arteries to endothelium dependent and independent vasodilators in patients with Raynaud's phenomenon," European Journal of Clinical Investigation, vol. 25, no. 3, pp. 182-185, 1995.

[97] P. J. W. Smith, C. J. Ferro, D. S. McQueen, and D. J. Webb, "Impaired cholinergic dilator response of resistance arteries isolated from patients with Raynaud's disease," British Journal of Clinical Pharmacology, vol. 47, no. 5, pp. 507-513, 1999.

[98] J. L. Cracowski, S. Girolet, B. Imbert et al., "Effects of shortterm treatment with vitamin $\mathrm{E}$ in systemic sclerosis: a double blind, randomized, controlled clinical trial of efficacy based on urinary isoprostane measurement," Free Radical Biology and Medicine, vol. 38, no. 1, pp. 98-103, 2005.

[99] M. E. Mavrikakis, J. P. Lekakis, C. M. Papamichael, K. S. Stamatelopoulos, C. C. Kostopoulos, and S. F. Stamatelopoulos, "Ascorbic acid does not improve endothelium-dependent flow-mediated dilatation of the brachial artery in patients with Raynaud's phenomenon secondary to systemic sclerosis," International Journal for Vitamin and Nutrition Research, vol. 73, no. 1, pp. 3-7, 2003.

[100] F. Salsano, C. Letizia, M. Proietti et al., "Significant changes of peripheral perfusion and plasma adrenomedullin levels in N-acetylcysteine long term treatment of patients with sclerodermic Raynauds phenomenon," International Journal 
of Immunopathology and Pharmacology, vol. 18, no. 4, pp. 761-770, 2005.

[101] P. Sambo, D. Amico, R. Giacomelli et al., "Intravenous Nacetylcysteine for treatment of Raynaud's phenomenon secondary to systemic sclerosis: A pilot study," Journal of Rheumatology, vol. 28, no. 10, pp. 2257-2262, 2001.

[102] G. L. Tipoe, T. M. Leung, M. W. Hung, and M. L. Fung, "Green tea polyphenols as an anti-oxidant and antiinflammatory agent for cardiovascular protection," Cardiovascular and Hematological Disorders-Drug Targets, vol. 7, no. 2, pp. 135-144, 2007.

[103] A. Pannala, C. A. Rice-Evans, B. Halliwell, and S. Singh, "Inhibition of peroxynitrite-mediated tyrosine nitration by catechin polyphenols," Biochemical and Biophysical Research Communications, vol. 232, no. 1, pp. 164-168, 1997.

[104] C. Rice-Evans, "Implications of the mechanisms of action of tea polyphenols as antioxidants in vitro for chemoprevention in humans," Proceedings of the Society for Experimental Biology and Medicine, vol. 220, no. 4, pp. 262-266, 1999.

[105] M. Sabetkar, S. Y. Low, N. J. Bradley, M. Jacobs, K. M. Naseem, and K. Richard Bruckdorfer, "The effect of epigallocatechin-gallate on protein tyrosine nitration in platelets," Platelets, vol. 19, no. 4, pp. 282-292, 2008.

[106] N. Khan, F. Afaq, M. Saleem, N. Ahmad, and H. Mukhtar, "Targeting multiple signaling pathways by green tea polyphenol (-)-epigallocatechin-3-gallate," Cancer Research, vol. 66, no. 5, pp. 2500-2505, 2006.

[107] H. K. Na and Y. J. Surh, "Intracellular signaling network as a prime chemopreventive target of (-)-epigallocatechin gallate," Molecular Nutrition and Food Research, vol. 50, no. 2, pp. 152-159, 2006.

[108] A. Chen, L. Zhang, J. Xu, and J. Tang, "The antioxidant (-)-epigallocatechin-3-gallate inhibits activated hepatic stellate cell growth and suppresses acetaldehyde-induced gene expression," Biochemical Journal, vol. 368, part 3, pp. 695704, 2002.

[109] F. Yumei, Y. Zhou, S. Zheng, and A. Chen, "The antifibrogenic effect of (-)-epigallocatechin gallate results from the induction of de novo synthesis of glutathione in passaged rat hepatic stellate cells," Laboratory Investigation, vol. 86, no. 7, pp. 697-709, 2006.

[110] R. Sakata, T. Ueno, T. Nakamura, M. Sakamoto, T. Torimura, and M. Sata, "Green tea polyphenol epigallocatechin-3gallate inhibits platelet-derived growth factor-induced proliferation of human hepatic stellate cell line LI90," Journal of Hepatology, vol. 40, no. 1, pp. 52-59, 2004.

[111] H. Asaumi, S. Watanabe, M. Taguchi et al., "Green tea polyphenol (-)-epigallocatechin-3-gallate inhibits ethanol-induced activation of pancreatic stellate cells," European Journal of Clinical Investigation, vol. 36, no. 2, pp. 113-122, 2006.

[112] M. Meng, Y. Q. Li, M. X. Yan, Y. Kou, and H. B. Ren, "Effects of epigallocatechin gallate on diethyldithiocarbamate-induced pancreatic fibrosis in rats," Biological and Pharmaceutical Bulletin, vol. 30, no. 6, pp. 1091-1096, 2007.

[113] Q. Zhang, A. P. Kelly, L. Wang et al., "Green tea extract and (-)-epigallocatechin-3-gallate inhibit mast cell-stimulated type I collagen expression in keloid fibroblasts via blocking PI-3K/Akt signaling pathways," Journal of Investigative Dermatology, vol. 126, no. 12, pp. 2607-2613, 2006.

[114] A. Dooley, X. Shi-Wen, N. Aden et al., "Modulation of collagen type I, fibronectin and dermal fibroblast function and activity, in systemic sclerosis by the antioxidant epigallocatechin-3-gallate," Rheumatology, vol. 49, no. 11, pp. 2024-2036, 2010.
[115] H. L. Li, Y. Huang, C. N. Zhang et al., "Epigallocathechin-3 gallate inhibits cardiac hypertrophy through blocking reactive oxidative species-dependent and -independent signal pathways," Free Radical Biology and Medicine, vol. 40, no. 10, pp. 1756-1775, 2006.

[116] H. Nishikawa, K. Wakano, and S. Kitani, "Inhibition of NADPH oxidase subunits translocation by tea catechin EGCG in mast cell," Biochemical and Biophysical Research Communications, vol. 362, no. 2, pp. 504-509, 2007.

[117] S. K. Katiyar, F. Afaq, A. Perez, and H. Mukhtar, "Green tea polyphenol (-)-epigallocatechin-3-gallate treatment of human skin inhibits ultraviolet radiation-induced oxidative stress," Carcinogenesis, vol. 22, no. 2, pp. 287-294, 2001.

[118] S. K. Katiyar, "UV-induced immune suppression and photocarcinogenesis: chemoprevention by dietary botanical agents," Cancer Letters, vol. 255, no. 1, pp. 1-11, 2007.

[119] N. Sriram, S. Kalayarasan, and G. Sudhandiran, "Epigallocatechin-3-gallate exhibits anti-fibrotic effect by attenuating bleomycin-induced glycoconjugates, lysosomal hydrolases and ultrastructural changes in rat model pulmonary fibrosis," Chemico-Biological Interactions, vol. 180, no. 2, pp. 271-280, 2009.

[120] Y. Yasuda, M. Shimizu, H. Sakai et al., “(-)-Epigallocatechin gallate prevents carbon tetrachloride-induced rat hepatic fibrosis by inhibiting the expression of the PDGFR $\beta$ and IGF1R," Chemico-Biological Interactions, vol. 182, no. 2-3, pp. 159-164, 2009.

[121] M. C. Zhen, Q. Wang, X. H. Huang et al., "Green tea polyphenol epigallocatechin-3-gallate inhibits oxidative damage and preventive effects on carbon tetrachloride-induced hepatic fibrosis," Journal of Nutritional Biochemistry, vol. 18, no. 12, pp. 795-805, 2007. 


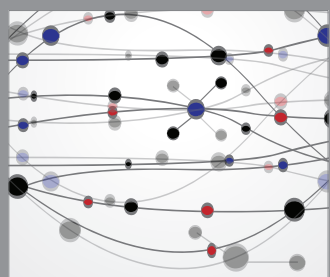

The Scientific World Journal
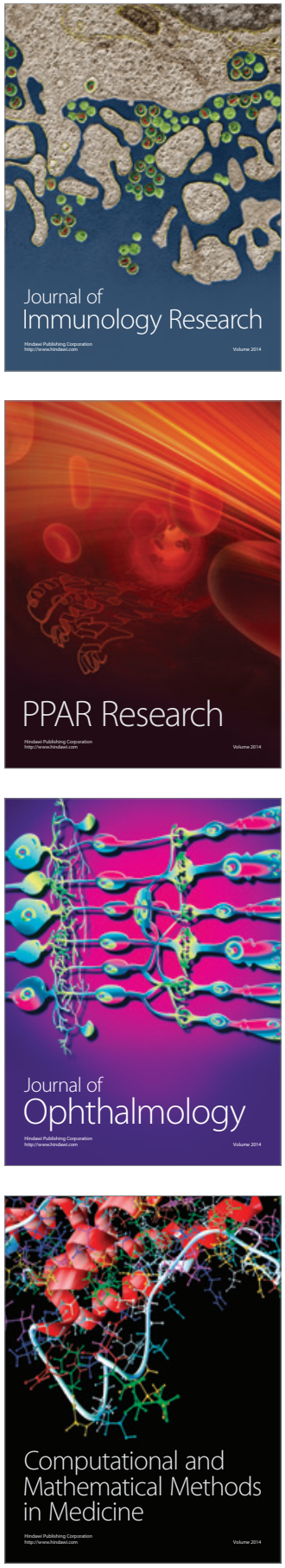

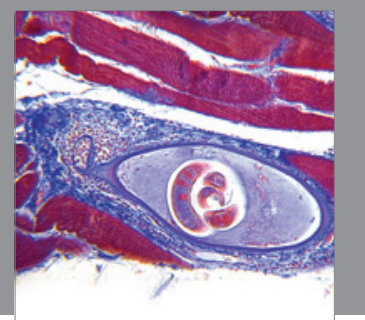

Gastroenterology

Research and Practice
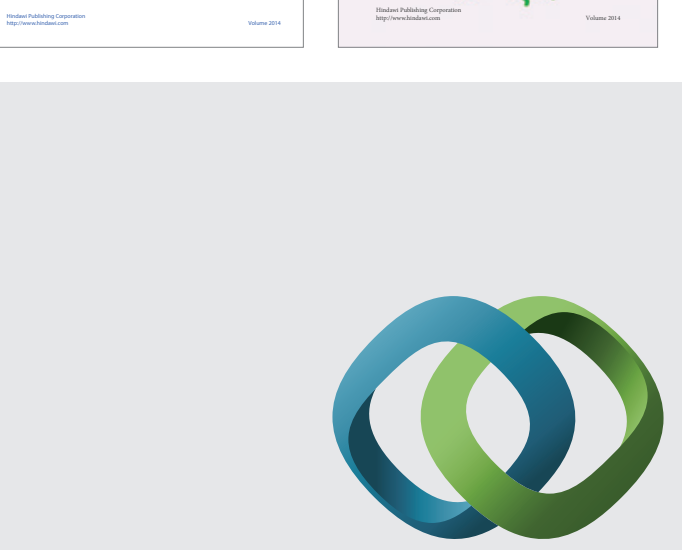

\section{Hindawi}

Submit your manuscripts at

http://www.hindawi.com
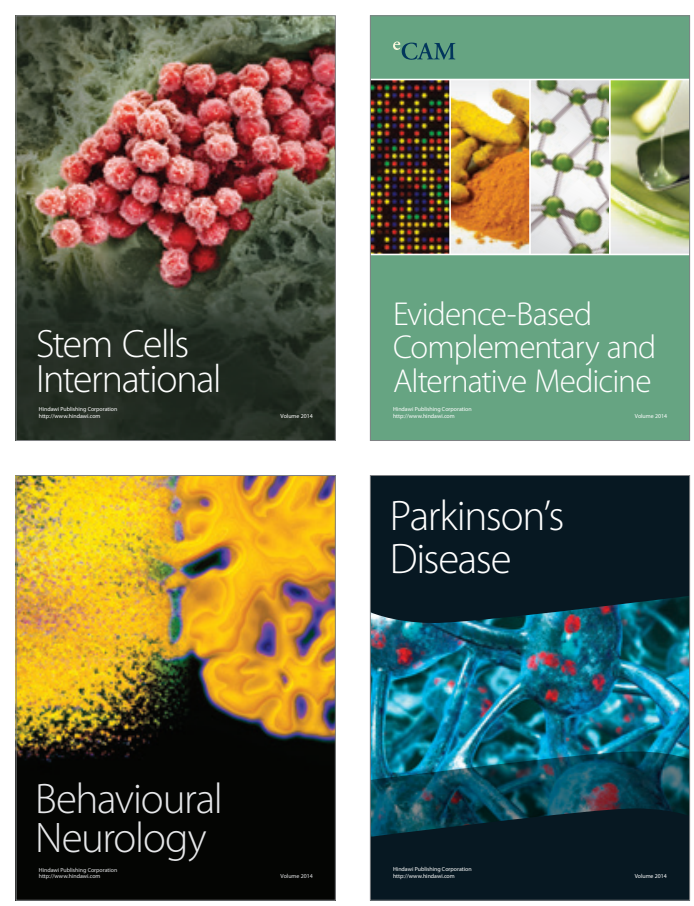

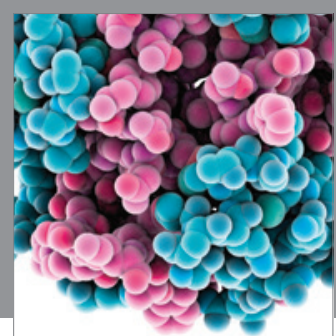

Journal of
Diabetes Research

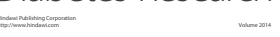

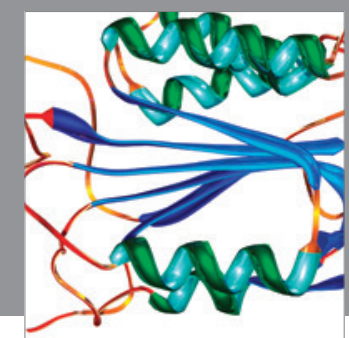

Disease Markers
